\title{
Nano- and Micro-materials in the Treatment of Internal Bleeding and Uncontrolled Haemorrhage
}

Elizabeth Gaston, BSc ${ }^{1,2}$, John F. Fraser, $\mathrm{PhD}^{3}$, Zhi Ping Xu, $\mathrm{PhD}^{1}$, Hang T. Ta, $\mathrm{PhD}^{1, *}$

${ }^{1}$ Australian Institute for Bioengineering and Nanotechnology, the University of Queensland, Brisbane, QLD 4072, Australia

2 Department of Bioengineering, Clemson University, Clemson, SC 29634, USA

${ }^{3}$ Faculty of Medicine, Critical Care Research Group, Prince Charles Hospital and the University of Queensland, Brisbane, Brisbane, QLD 4032, Australia

*Correspondence to Hang T. Ta ( Building 75, Cnr of College and Cooper Road, Brisbane, QLD 4072, Australia)

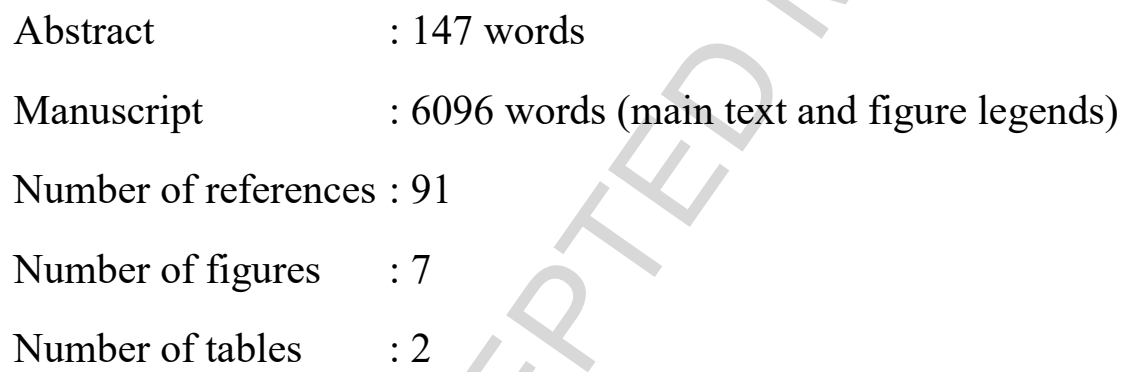

\section{Acknowledgements}

This work is funded by Australian National Health and Medical Research Council (H.T.T: APP1037310). 


\title{
Nano- and Micro-materials in the Treatment of Internal Bleeding and Uncontrolled Haemorrhage
}

\begin{abstract}
Internal bleeding is defined as the loss of blood that occurs inside of a body cavity. After a traumatic injury, haemorrhage accounts for over $35 \%$ of pre-hospital deaths and $40 \%$ of deaths within the first 24 hours. Coagulopathy, a disorder in which the blood is not able to properly form clots, typically develops after traumatic injury and results in a higher rate of mortality. The current methods to treat internal bleeding and coagulopathy are inadequate due to the requirement of extensive medical equipment that is typically not available at the site of injury. To discover a potential route for future research, several current and novel treatment methods have been reviewed and analysed. The aim of investigating different potential treatment options is to expand available knowledge, while also call attention to the importance of research in the field of treatment for internal bleeding and haemorrhage due to trauma.
\end{abstract}

Keywords: nanomaterials, internal bleeding, haemorrhage, coagulopathy, trauma

\section{Introduction}

Severe bleeding accounts for approximately one third of total deaths in hospitals that occur due to trauma events [1]. Haemorrhage is the primary cause of preventable military death and the second cause of civilian trauma deaths [2]. Studies indicate that the majority of injury mortality during civilian and military trauma occurs in the prehospital period, defined as the time between injury and admission to the hospital [3]. Current protocol for the treatment of internal bleeding relies on the usage of extensive medical equipment such as computed tomography scanners, tests to monitor coagulation, and in some cases, surgical tools [4]. The absence of an effective, safe, and quick treatment method results in preventable deaths during the pre-hospital and clinical phases. While on the battlefield, there is little to no standard protocol established for the treatment of internal bleeding and haemorrhage. Unlike external injuries, internal injuries cannot be treated by 
compression and thus intravenously administered treatment to induce coagulation and halt bleeding would be ideal. In areas where medical equipment is not readily available, quick and effective drugs are necessarily administered intravenously on the site of injury. There are many complications to consider when developing a solution which induces coagulation due to the harmful side effects to excessive blood clotting, such as pulmonary embolism and deep vein thrombosis [5]. In order to design a safe and effective means of treatment for internal bleeding and haemorrhage, it is necessary to summarise and understand current innovations and options available. This review article aims to provide an overview of current and potential treatment options of internal bleeding and haemorrhage in both clinical and pre-hospital phases. Many studies on the use of nano/micro-materials as hemostatic agents have been conducted [6-21] and several researchers in this field have come to the conclusion that nano/micro-materials would be useful in the detection and maintenance of internal bleeding and haemorrhage.

\section{Coagulation}

Thrombohemorrhagic balance is maintained in the body by interactions between coagulation and the fibrinolytic system [22]. Primary haemostasis is defined as the process where platelets interact with parts of a damaged vessel wall, which leads to the formation of a platelet plug [23]. To initiate platelet adhesion, fibrinogen and Von Willebrand factor must be present. Once platelets adhere to the injury site, they are activated due to their exposure to the damaged endothelium and vessel wall [23]. Thrombin plays a role in the activation of platelets, regulation of factors important for coagulation, and the cleavage of proteins necessary to form blood clots [24]. Upon activation, blood platelets aggregate, leading to the formation of a platelet plug, which temporarily seals off the vascular injury [23]. Thrombin cleaves fibrinogen to fibrin, which forms the mesh of the clot, and also activates factor XIII which regulates the cross-linking of fibrin and thus can improve the strength of a clot [24]. The coagulation cascade has been illustrated in Figure 1 shown below. 
Maintaining haemostasis is one of the most important aspects to consider during the treatment of internal bleeding and haemorrhage.

\section{Diagnosis}

Symptoms of shock include tachycardia, hypotension and evidence of end organ hypoperfusion [25]. Focused abdominal sonography for trauma (FAST), Computed tomography (CT) scanners, and angiography are typically used to find the source of the bleed [4]. CT scanning has been an established method of the detection and location of internal bleeds and gives information necessary to determine whether surgical intervention or angiographic intervention is needed [26]. CT scans are quick and highly accurate but pose several major problems such as steep costs, high doses of radiation, and the chance for data misinterpretation [27]. Recently, there has been much enthusiasm toward the use of focused abdominal sonography for trauma due to the ability to scan in the emergency/ICU department, its efficacy and immediate result [28].

Along with the detection and location of an internal bleed, it is important for tests to be performed to ensure blood products remain at equilibrium [29]. Prothrombin time and activated partial thromboplastin time are typical factors to be evaluated in effort to monitor haemostasis, the physiological process that stops bleeding at the site of an injury [30]. In order to evaluate these factors, viscoelastical haemostatic assays (VHAs) such as thromboelastography (TEG) and rotational thromboelastometry (ROTEM) are used in standard protocol [31]. VHAs measure the changes in elastic properties of whole blood during the process of clot formation and breakdown [30]. The factors measured are defined in Table 1 [32]. TEG and ROTEM are similar in that they measure physical properties of blood clot strength, such as maximal amplitude and shear elastic modulus, to determine haemostatic status of patients, but differ in hardware used to hold the blood sample [33]. It is important to note that TEG and ROTEM cannot be used to measure platelet inhibition in patients who use aspirin and adenosine 5'-diphosphate receptor inhibitors such as clopidogrel, effient, or 
ticagrelor. In this case, TEG platelet mapping assays or the multiple electrode impedance aggregometer multiplate must be used [34].

\section{Pathophysiology}

Coagulopathy, or a condition where the blood is unable to properly form clots, commonly develops in trauma situations due to acidosis, hypothermia, and loss of coagulation factors, and is typically associated with poor outcomes and an increase in mortality rate [35]. The disruption of equilibrium of blood clotting factors caused by trauma is associated with the development of acute traumatic coagulopathy (ATC), and in some cases can result in a 4-fold increase in mortality [36]. Fibrinogen, which is cleaved into fibrin to produce blood clots, proves to be one of the most important factors to consider during treatment of ATC and is usually the first factor to drop below reference values during bleeding and trauma [37]. Haemorrhage and coagulopathy can lead to direct tissue injury, shock, and hypoperfusion, which can cause systemic anticoagulation and hyperfibrinolysis, a condition where the breakdown of fibrin is potentially greater than fibrin formation and therefore threatens the integrity of a blood clot $[35,38]$. Haemophilia, anticoagulation, hyperfibrinolysis, hyperfibrinogenemia, or low levels of fibrinogen, and compromised thrombin generation are associated with worse outcomes and an increase in mortality rate $[35,36,38]$.

\section{Current Treatments of Internal Bleeding and Coagulopathy}

Compression and the use of a tourniquet prove to be effective means to control haemorrhage due to external injuries and open extremity injuries, but internal bleeding requires more extensive treatment [39]. Current standard of protocol for the treatment of haemorrhage and internal injury, with availability of proper medical equipment, starts with maintaining tissue oxygenation by aggressive fluid administration to restore blood volume. It is much debated whether this aggressive approach should be used due to an increase in pressure on the wound, which can cause movement of 
blood clots, dilution of coagulation factors, and unwanted cooling of the patient [40]. Permissive hypotension, or aiming to achieve a lower blood pressure than normal, such as a systolic blood pressure of $80-90 \mathrm{mmHg}$, reduces the chances of the unwanted effects of aggressive resuscitation using high doses of fluids [40]. After fluid administration, it is recommended to reduce heat loss and warm up the body in order to diminish the effects of hypothermia, which include altered platelet function, impaired coagulation factor function, enzyme inhibition, and fibrinolysis [41, 42]. For patients with severe haemorrhagic shock, ongoing bleeding and coagulopathy, damage control surgery is recommended [40]. Damage control surgeries work to achieve control of haemorrhage, exploration, control of contamination, definitive packing and rapid abdominal closure [43].

During the pre-hospital period, such as while on the battlefield, non-compressible bleeding treatment options are extremely limited and haemorrhage control in most of these cases requires surgical approach [44]. Current standard procedure for the treatment of catastrophic abdominal haemorrhage is to immediately evacuate to allow rapid surgical intervention [45]. Massive transfusion protocol is sometimes used, but often achieving this sort of haemorrhage control early on is difficult due to circumstances such as on-going gunfire, remoteness, and skill level of care providers [46]. After referring to current protocol for the treatment of internal bleeding and haemorrhage in pre-hospital and clinical phases, it is evident that alternative treatment methods are necessary.

Patients in clinical settings suffering from coagulopathy may also get means of treatment by blood transfusion or the use of drugs that inhibit the breakdown of clot formation [47]. It is clear that transfusions improve survival rates, but there is much debate on the ideal transfusion ratio of blood to blood products [48]. To treat hyperfibrinolysis, some physicians will use antifibrinolytic drugs to prevent the breakdown of fibrin in the mesh of blood clots [47]. The mostly studied antifibrinolytic, transexamic acid (TXA), inhibits plasminogen activation and therefore prevents fibrin clot lysis [47]. Research studies show that upon usage on trauma injuries within 8 hours, TXA significantly reduces 
mortality and deaths resulting from bleeding without significantly increasing thrombotic complications [47]. The Clinical Randomization of an Antifibrinolytic in Significant Haemorrhage trial (CRASH-2) was a large, randomized controlled trial which was the first to show a reduction in mortality and recommend the use of TXA in bleeding trauma patients [49]. It is proposed by several researchers that TXA should become a standard protocol in trauma management.

In order to treat patients with hyperfibrinogenemia, fibrinogen supplementation can be provided by fibrinogen concentrate, cryoprecipitate, or frozen plasma $[50,51]$. The fibrinogen content of these supplements is much debated and requires more research to test the efficacy and safety of this treatment [52]. Recombinant activated factor VII (rFVIIa) is used in some cases for the management for preoperative haemorrhage due to the inducing effect on haemostasis, especially with patients with haemophilia, a disorder in which blood does not clot due to the lack of proper bloodclotting proteins [53]. Research studies show that rFVIIa proved to be an effective method to induce blood clotting. However, an Australian study found that $11 \%$ of patients treated with rFVIIa suffered from thromboembolic adverse events, and it was not effective on patients suffering from acidosis [54]. Current approaches used to stop the breakdown of clots are useful, but could increase the risk of thromboembolism and therefore other approaches should be studied.

\section{Novel Potential Treatments of Internal Bleeding}

\section{Polymeric nanoparticles}

Bertram et al have designed a synthetic platelet that is stable at room temperature, safely administered intravenously, non-immunogenic, and able to halt bleeding [6]. The design relies on the usage of polymer engineering to allow for rapid halting of bleeding by a self-assembling peptide [55]. The design is shown in Figure 2A and consists of polylactic-co-glycolic acid-poly-L-lysine (PLGA-PLL) block copolymers in conjunction with polyethylene glycol (PEG) arms with amino acid sequence Arg-Gly-Asp (RGD) ends to allow for activated platelets to attach and thus form a 
blood clot [6]. A scanning electron microscope micrograph of the synthetic platelets is shown in Figure 2B. The platelet membrane glycoprotein IIb/IIIa complex serves as a receptor for fibrinogen, von Willebrand factor, fibronectin, and vetronectin, all of which contain the amino acid sequence RGD. The interaction of these proteins with the receptor site is mediated by RGD and therefore initiated to cause blood clotting [56]. Synthetic platelet interaction with clots via the fibrin mesh can be seen in Figure 2C [6]. Researchers discovered that the greatest adhesion occurred as amino acids were added to the side chains, thus making the GRGDS formulation more effective. This design was tested on rodents with severed arteries and proved to be effective by reducing bleeding time by approximately $23 \%$ when compared to no injection [6]. When compared to no injection and a saline injection, the synthetic platelets resulted in a significant reduction in bleeding time (Figure 2D) [6]. Although the synthetic platelets have yet been tested for biocompability and cytoxicity, it is hypothesized that the platelets will be safe to use in the body due to the lack of platelet activation exhibited during in vivo analysis on rats [6]. Comparable research was done by Lashof-Sullivan et al. using haemostatic nanoparticles, and results proved that the nanoparticles were effective [8]. When tested on animals suffering from blast trauma and multi-organ haemorrhage, the study showed that the haemostatic nanoparticles improved survival to $90 \%$ compared to $60 \%$ with no treatment [8]. In both studies, no side effects were noted. More research is necessary before potentially facing human trials, although platelet mimicking nanoparticles prove to be a very promising route for researchers $[6,8]$.

Similarly, researchers at Case Western Reserve University studied the usage of nanoparticles to reduce bleeding, and aimed to improve the efficiency of activated platelet targeting [8]. Prior to this study, intravenously injectable nanoparticles that augment haemostasis after injury were prepared using biodegradable block copolymers PLGA and PLL with PEG arms terminated with the amino acid sequence arginine-glycine-aspartic acid (GRGDS) [8]. Nanoparticle targeting of active platelets takes advantage of ligand-receptor, antigen-antibody, and other forms of molecular 
recognition to deliver a drug to a specific location [57]. To optimize the usage of these nanoparticles, researchers noted that ligand density is a critical component in the targeting of nanoparticles [58, 59]. Work in this study demonstrates the importance of optimizing the ligand density and thus lays a model for other researchers to determine optimal ligand concentration parameters [7]. Fakhari et al studied the effects of varying the ligand density on nanoparticles made of PLGA with the peptide cLABL and discovered that the optimal ligand density was near 50/50 [60]. In the previous study at Case Western Reserve University focusing on the development of nanoparticles that could induce coagulation, survival rate of animals with liver injury that received the nanoparticles was around $80 \%$ [7]. In the same study, researchers optimized the ligand density and found that after a 100-fold increase in targeting ligand concentration, a 92\% survival rate was achieved using the GRGDS nanoparticles [7]. Studies on the ligand density and concentration are significant to optimize the efficacy of the targeting properties of ligands, in order to better form blood clots.

Hubbard et al also used the peptide sequence, GRGDS, in conjugation with nanoparticles made of PLGA, PLL, and PEG to combat the effects of blast trauma [9]. Primary blast lung injury is a common cause of death resulting from internal haemorrhage caused by the detonation of improvised explosive devices (IEDs) [61]. PLGA is a polymer typically used for drug delivery due to its biodegradability, drug biocompatibility, suitable biodegradation kinetics and mechanical properties, and ease of processing [62-64]. Since the nanoparticles are based on PLGA, the researchers took advantage of drug delivery capabilities and used the nanoparticles to carry a steroid, dexamethasone (Figure 3A) [9]. Dexamethasone has been shown to reduce programmed cellular death that results from haemorrhage in the brain while also reducing inflammation after injury [65]. Dexamethasone proved to be a suitable and biocompatible steroid-link due to its anti-inflammatory properties and non-effect on coagulation [9]. A scanning electron microscope image of the particles loaded with dexamethasone can be seen in Figure 3B. Particles were tested for treatment of primary blast lung injury in rodent models, and it was found that the dexamethasone-loaded haemostatic 
nanoparticles (hDNP) resulted in an increase in oxygen saturation and lower percent injury (Figure 3C \& D) [9]. Steroid loaded nanoparticles prove to be an optimistic agent for therapeutic treatment in traumatic injuries, but require more testing to evaluate their toxicity and determine if they are safe to use in the body.

\section{Silica and Iron Oxide Nanoparticles}

Meddahi-Pellé et al. took a different route to achieve haemostasis by demonstrating that iron oxide nanoparticles and silica nanoparticle aqueous solutions could be used for wound closure and repair in skin and liver injuries in rat models [10]. Iron oxide nanoparticles are metabolizable, and could potentially be used for magnetic resonance imaging [66]. Meddahi-Pellé et al. found that bleeding control and tissue repair can be both achieved through the process of nanobridging [10]. The concept of nanobridging starts with the droplet of a nanoparticle solution being spread over the wound surface of a tissue. The wound edges are then brought together by gentle manual pressure and then the nanoparticles absorbed onto the tissue will begin linking the wound edges together [10]. In order to test the nanoparticles, they were deposited into the bleeding injury area with a pipette, and proved to bring edges of the wound together and induce haemostasis after just one minute [10]. By demonstrating strong adhesion and permanent haemostasis, this study proves the usage of nanoparticles and could lead to a future-generation of tissue adhesives. Before clinical testing, the nanoparticles must be tested for safety and toxicity to ensure biocompatibility and haemocompatability.

\section{Liposomes}

Modery-Pawlowski et al. studied the usage of liposomes with surfaces covered with collagenand VWF-binding peptides (CBP: TRYLRIHPQSWVHQI and VBP ([Glycine-ProlineHydroxyproline $]_{7}$ ) to mimic platelet adhesion, and fibrinogen-mimetic peptide (FMP) with sequence of cyclo-CNPRGDY(OEt)RC to promote platelet aggregation (Figure 4A, B, C) [11]. This research 
focused on the design of nanoparticles that could mimic both platelet adhesion and platelet aggregation, considering both are functions required for effective haemostasis [11]. A study by Okamura et al. supported this hypothesis and found that co-administering latex particles with functions of platelet-mimetic aggregation and platelet-mimetic adhesion resulted in higher haemostatic potential [21]. In this study, latex beads were functionalized with fibrinogen gammachain carboxy-terminal sequence HHLGGAKQAGDV (H12), which recognizes activated platelets at low shear rates, and a recombinant water-soluble moiety of the platelet glycoprotein (rGPIbalpha), which recognizes von Willebrand factor at high shear rates. These platelet substitutes have shown hemostatic properties over a wide range of shear rates. Results from Modery-Pawlowski et al. found that liposomes decorated with both VBP and CBP had higher adhesion compared to liposomes with only VBP or CBP [11]. The study also demonstrated that nanoparticles that combine both platelet adhesion and aggregation mimetic peptides more effectively caused coagulation and treated bleeding and haemorrhage (Figure 4D).

Okamura et al. studied platelet substitutes using phospholipid vesicles that bear on their surface a dodecapeptide, HHLGGAKQAGDV (H12) [12]. This peptide recognizes the active form of glycoprotein IIb/IIIa (GPIIb/IIIa) on the surface of activated platelets. When the peptide adheres, the formation of GPIIb/IIIa changes from a silent form to an activated form [67-69]. When activated, GPIIb/IIIa acts as a receptor for fibrinogen and provides three platelet interaction sites: a tetrapeptide containing RGD sequences such as RGDF and RGDS and a dodecapeptide, H12 [70]. The study by Okamura et al. focused on the usage of the dodecapeptide, H12, instead of fibrinogen [12]. In combination with PEG, the H12 vesicles proved to be effective as they did not interact with nonactivated platelets but with activated platelets via their GPIIb/IIIa receptors, thus facilitating platelet accumulation [12]. This research suggests that the usage of dodecapeptide H12 could be a potential alternative to human platelet concentrates for the treatment of internal bleeding.

\section{Calcium carbonate-based microparticles}


Baylis et al developed simple gas-generating microparticles consisting of calcium carbonate $\left(\mathrm{CaCO}_{3}\right)$ as potential hemostatic materials [13]. $\mathrm{CaCO}_{3}$ is commonly used in antacid tablets and drug formulations. $\mathrm{CaCO}_{3}$ rapidly produces carbon dioxide $\left(\mathrm{CO}_{2}\right)$ in acidic solutions, and can form porous microparticles that are able to adsorb protein, making it an ideal substance for self-fuelled drugcarrier particles. When $\mathrm{CaCO}_{3}$ particles were mixed with a solid organic acid such as protonated tranexamic acid (TXA- $\mathrm{NH}_{3}{ }^{+}$) and injected into buffered saline solution or whole blood, the particles reacted vigorously and self-travelled through the solutions at velocities of up to $1.5 \mathrm{~cm} / \mathrm{s}$. The transport of the particles was contributed by a combination of lateral propulsion, buoyant rise, and convection generated by the rapid production of gas bubbles (Figure 5A) [13]. When loaded with active thrombin, the microparticles were able to delivered therapeutics millimetres into the vasculature of wounds and worked effectively as a hemostatic agent. They were proved to halt severe haemorrhage in multiple mouse models of intraoperative and traumatic bleeding (Figure 5B-I). No signs of pain or distress were observed and the histological analysis of lung tissues showed no difference from controls, and therefore suggest that major embolism or severe toxicity did not occur. However, additional work is required to systemically evaluate safety and toxicity.

\section{Albumin microcapsules}

Levi et al. investigated the effect of fibrinogen-coated albumin microcapsules on thrombocytopenic bleeding using models of immune thrombocytopenia and chemotherapy-induced thrombocytopenia in rabbits [14]. Albumin microspheres are useful in the delivery of drugs due to their physical and chemical stability and their capability of accommodating a large amount of drug molecules [71]. Fibrinogen plays a critical role in secondary haemostasis due to its involvement in platelet aggregation, and therefore was chosen for the potential development of a platelet substitute [72]. This study proved that the administration of fibrinogen-coated albumin microcapsules results in a reduction of bleeding in rabbits with thrombocytopenic [14]. Toxicity studies were completed using histological analysis of the organs and showed that there were no adverse effects of the 
administration of fibrinogen-coated albumin microcapsules [14]. In efforts to create fibrinogenconjugated albumin polymers to be as effective as Levi's platelet substitutes, Shinji et al. investigated the interaction of the fibrinogen-albumin polymers with Glycoprotein II/IIIa (GPIIb/IIIa) expressed on the activated platelets and the recruiting of circulating platelets [73]. Upon platelet activation, GPIIb/IIIa changes conformation, which increases the affinity of the receptor for fibrinogen and aids in the aggregation process [74]. The interaction of the fibrinogen-coated albumin microcapsules and platelets is shown in Figure 6A, while the presence of microspheres at the site of the haemostatic plug can be shown in Figure 6B [14]. Results showed that the number of platelets attached increased as the amount of fibrinogen-albumin polymers increased, indicating that the platelets were recruited by the attached fibrinogen-albumin polymers [73]. These studies indicate that fibrinogen-coated albumin microcapsules and polymers can be beneficial in the process of primary haemostasis and could lead to further treatments of internal bleeding and haemorrhage [14, 73].

\section{Hydrogel Microparticles}

Cationic hydrogel particles as a hemostatic agent have been developed and tested by Behrens et al and proved to induce blood aggregate formation as well as bulk blood coagulation inhibition [15]. Hydrogel particles are relatively inexpensive and prove to be a promising route for the treatment of internal bleeding and haemorrhage. N-(3-aminopropyl)methacrylamide hydrochloride (APM) hydrogel particles were synthesized by inverse suspension polymerization. The hydrogel particles have an average diameter ranging from $450 \mu \mathrm{m}$ to $1250 \mu \mathrm{m}$ [15]. In order for the particles to quickly block blood flow, they are capable of rapidly swelling to over $1000 \%$ in size through their high positive charge and low crosslink density [15]. The hydrogel particles were tested on rat injury and ovine liver laceration models, and proved to be an effective means to block blood flow, evidenced by the creation of significant haemostatic plugs [15]. The study by Behren et al. proves that hydrogel particles are a potential means of treatment, but require removal from the body after treatment, and 
thus more research is required to potentially add a degradable property. Toxicity and biocompatibility tests of the material were not reported, but with future research and testing, hydrogel particles could be a useful haemostatic agent.

\section{Synthetic Polymers}

An engineered homeostatic polymer (PolySTAT - Figure 7A) that circulates in the blood, identifies sites of injury, and promotes blood clot formation to stop bleeding has been developed using poly-hydroxyethyl methacrylate (PolyHEMA) grafted with fibrin-binding peptide to induce haemostasis [16]. PolySTAT stabilizes the blood clots via fibrin crosslinking. Researchers drew inspiration for the synthetic haemostatic polymer from tranglutaminase Factor XIIIa (FXIIIa), the factor that stabilizes blood clots by crosslinking the fibrin matrix [16]. FXIIIa supplementation was found to produce fibrin networks with thinner fiber diameters, greater fiber density, and smaller pores, which are all factors that contribute to clot stiffness and resistance to fibrinolysis [75, 76]. PolySTAT-modified fibrin had smaller pores interspersed throughout a dense fibrin mesh compared to PBS and PolySCRAM controls and hFXIIIa-crosslinked fibrin, which all had distinct, loosely interwoven fibers and larger pore sizes (Figure 7B). The in vitro evaluation revealed that PolySTAT increased clotting kinetics, increased clot strength, and delayed clot breakdown [16]. While administered intravenously in rats, PolySTAT reduced blood loss, improved tissue perfusion, and enhanced survival rate (Figure 7C \& D) [16]. From these results, PolySTAT proved to be an effective agent to induce coagulation, and could be potentially used to treat acute bleeding with patients suffering from clotting disorders such as FXIII deficiency and haemophilia [16].

To create a means of pre-surgical intervention for non-compressible abdominal haemorrhage, a self-expanding polyurethane foam was developed and studied [17-19]. In order for the foam to expand, the system involves mixing and injecting two liquid phases, a polyol phase and an isocyanate phase $[77,78]$. When the reaction occurs, the material volume expands 30 times of its initial volume and then a gelling reaction transforms the material from the liquid phase to the solid 
polymer foam [17]. Research by Duggan et al. found that there was a significant increase in survival rate following administration of the polymer 10 minutes after liver injury [17]. The polyurethane polymer was developed to spread throughout the abdominal cavity in the presence of haemorrhage and create conformal contact with sites of injury and thus stop bleeding [17]. Studies found that this method is effective and has many potential benefits, but requires a midline laparotomy for extraction, so its usage is limited $[17,18]$. Mesar et al researched this method and determined the optimal dosage to allow for acceptable intra-abdominal pressure to eliminate some side effects, such as focal bowel lesions [19]. More research, such as biocompatibility and toxicity tests, are necessary for this to become a treatment protocol $[17,19]$.

\section{Chitosan Nanofiber Mat}

$\mathrm{Gu}$ et al. studied electrospinning of pure chitosan to synthesize potential nanofibrous haemostatic material [20]. Chitosan is a natural polymer with very advantageous biological properties such as negligible immune response following implantation, injection, topical application, and ingestion [79]. Electrospinning is used to produce nanoscale fibers from polymers and produces nanofibers with desirable characteristics such as a high area to volume ratio [80]. The density of nanofibers restricts cell growth and mass transport of nutrients and metabolic waste, and also causes slow absorbance of water or blood due to the nanofiber structures [20]. Chitosan nanofiber mat with enlarged porosity was achieved by $\mathrm{Gu}$ et al using ultra-sonication, which significantly decreased water absorption time. The nanofiber mat was tested on the blood of rabbits and its blood clotting efficiency was 1.35- and 3.41-fold better than the efficiencies of other materials such as Surgicel (Johnson \& Johnson Medical, USA) and chitosan sponge, respectively. Although no tests were completed on the cytoxicity of the material, the nanofiber mat can be hypothesized to be safe to use in the body due to Chitosan's strong biocompatibility and biodegradability. The results found indicate that sonicated chitosan nanofiber mat has a strong potential to be used as a haemostatic agent [20]. 


\section{Biocompatibility of Potentially Treatment Materials}

The development of novel biomaterials, biomedical devices, or tissue-engineered objects requires an understanding of the biological responses to implanted materials, including the inflammatory response and macrophage foreign body reaction [81]. A review of the biocompatibility of implanted device concluded that the foreign body reaction depends on properties such as shape, size, surface chemistry and roughness, design, morphology and porosity, composition, sterility issues, contact duration, and degradation [82]. Whether a biomaterial shows favorable responses when implanted depends on corrosion resistance and toxicity [83]. Common polymers used in biomedical devices include Polyglycolide (PGA), Polylactide (PLA), and Polylactide-co-glycolide (PLGA) due to their degradation rates and erosion mechanisms [84]. Potential treatment materials for the treatment of internal bleeding and haemorrhage must also be evaluated for haemocompability due to their direct contact with blood. Platelet function, inflammatory response, coagulation, and hemolysis are important variables to consider when evaluating a material's haemocompatability [85]. Many of the research studies completed had yet to complete any in vivo or in vitro testing of the biocompatibility, toxicity, and safety in the body. It can be assumed that this is due to the research being in the preliminary stages. Before any of the novel treatments studied can be allowed for clinical trials and further testing, analysis on the features discussed is imperative.

\section{Perspectives}

After reviewing the current and novel methods of treatments for internal bleeding and haemorrhage, it is evident that there is much research left to be done in this field. Current treatments are effective, but pose many high risks and complications to the patients. New methods are promising, but are in the preliminary stages where possible complications are not clear. In prehospital phases, specifically while on the battle field, there is no solution available and thus many 
potentially preventable deaths occur. In a study by Kelly et al, $85 \%$ of deaths studied while on the battlefield were due to haemorrhage [86]. Haemorrhage is considered a main cause of death due to trauma caused by motor vehicle crashes and accidental injury [87]. In civilian settings, a study showed that haemorrhage is likely the cause of $20-40 \%$ of death following trauma [88]. The statistics previously discussed prove why research in the treatment of internal bleeding and haemorrhage is pertinent to the advancement of emergency and trauma medicine.

Current treatments available are quite limited and mainly rely on the usage of imaging and surgical equipment. Of the less invasive treatments currently available for internal bleeding and haemorrhage, such as transfusion, there are still many debates on proper protocol and standard procedure. As for treatments for coagulopathy, there is a severe lack in protocol and thus treatment varies worldwide. Of the methods studied, immediate surgical intervention proves to be the most effective means to stop internal bleeding, but forces patients to undergo extremely invasive procedures. For intravenously delivered drugs, it is difficult to determine which method is the most appropriate due to the large amount of questions unanswered about side effects and complications.

Novel methods of treatment for internal bleeding and haemorrhage prove to be effective in stopping blood clotting, but do not have research available on complications and solutions to complications that may arise. A summary of the studies reviewed is shown in Table 2. The use of peptides in order to give nanoparticles clotting capability proves to be a very promising route for researchers, but platelet targeting may not be as effective as proposed, so complications could arise from potential blood clotting in places outside of injury. Tissue plasminogen activator (tPA) is currently one of the only methods approved to treat stroke and to induce thrombolysis, or blood clot breakdown [89]. Tissue plasminogen activator is a naturally occurring enzyme that binds with fibrin and cleaves plasminogen into plasmin, and thus breaks down blood clots [90]. Administration of tPA proves to be an effective means of dissolving blood clots, but poses unacceptably high risks of bleeding in the brain and other tissues [91]. Due to the side effects of the formation of excess blood 
clots and the lack of a safe method to treat this, it is important to research alternatives to induce blood clotting that can also treat side effects if they occur.

In conclusion, much research is urgently needed in order to obtain a safe and effective means of treatments for internal bleeding and haemorrhage. Current available treatments only allow for that accessible to extensive medical equipment. In instances where patients are not able to reach a hospital, such as on the battlefield or in an emergency situation, a treatment method that can be delivered onsite is necessary. Current studies show that nanomaterials have potential in the treatment of internal bleeding and haemorrhage. Researchers currently are learning to optimize the usage of nanoparticles in order to target the source of bleeding and stop it, but lack the knowledge of potentially harmful side effects and complications. Due to the risks associated with the formation of excess blood clots, researchers should aim their studies to develop a treatment method that reduces the chances of costly side effects, while also find a means to treat complications if they should arise.

\section{References}

[1] Perel P, Prieto-Merino D, Shakur H, Clayton T, Lecky F, Bouamra O, et al. Predicting early death in patients with traumatic bleeding: development and validation of prognostic model. BMJ : British Medical Journal. 2012;345:5166.

[2] Champion HR BR, Roberts CP, Leppaniemi A. A profile of combat injury. The Journal of TRAUMA Injury, Infection, and Critical Care. 2003;54:13-9.

[3] Eastridge BJ, Hardin M, Cantrell J, Oetjen-Gerdes L, Zubko T, Mallak C, et al. Died of Wounds on the Battlefield: Causation and Implications for Improving Combat Casualty Care. Journal of Trauma and Acute Care Surgery. 2011;71:S4-S8.

[4] Spahn DR, Bouillon B, Cerny V, Coats TJ, Duranteau J, Fernández-Mondéjar E, et al. Management of bleeding and coagulopathy following major trauma: an updated European guideline. Critical Care. 2013;17:R76. 
[5] Cushman M. Epidemiology and Risk Factors for Venous Thrombosis. Seminars in hematology. 2007;44:62-9.

[6] Bertram JP, Williams CA, Robinson R, Segal SS, Flynn NT, Lavik EB. Synthetic Platelets: Nanotechnology to Halt Bleeding. Science translational medicine. 2009;1:22-38.

[7] Shoffstall AJ, Everhart LM, Varley ME, Soehnlen ES, Shick AM, Ustin JS, et al. Tuning ligand density on intravenous hemostatic nanoparticles dramatically increases survival following blunt trauma. Biomacromolecules. 2013;14:2790-7.

[8] Lashof-Sullivan MM, Shoffstall E, Atkins KT, Keane N, Bir C, VandeVord P, et al. Intravenously administered nanoparticles increase survival following blast trauma. Proceedings of the National Academy of Sciences of the United States of America. 2014;111:10293-8.

[9] Hubbard WB, Lashof-Sullivan MM, Lavik EB, VandeVord PJ. Steroid-Loaded Hemostatic Nanoparticles Combat Lung Injury after Blast Trauma. ACS Macro Letters. 2015;4:387-91.

[10] Meddahi-Pellé A, Legrand A, Marcellan A, Louedec L, Letourneur D, Leibler L. Organ Repair, Hemostasis, and In Vivo Bonding of Medical Devices by Aqueous Solutions of Nanoparticles. Angewandte Chemie (International Ed in English). 2014;53:6369-73.

[11] Modery-Pawlowski CL, Tian LL, Ravikumar M, Wong TL, Sen Gupta A. In vitro and in vivo hemostatic capabilities of a functionally integrated platelet-mimetic liposomal nanoconstruct. Biomaterials. 2013;34:3031-41.

[12] Okamura Y, Maekawa I, Teramura Y, Maruyama H, Handa M, Ikeda Y, et al. Hemostatic effects of phospholipid vesicles carrying fibrinogen gamma chain dodecapeptide in vitro and in vivo. Bioconjugate chemistry. 2005;16:1589-96.

[13] Baylis JR, Yeon JH, Thomson MH, Kazerooni A, Wang X, St John AE, et al. Self-propelled particles that transport cargo through flowing blood and halt hemorrhage. Sci Adv. 2015;1:e1500379. 
[14] Levi M, Friederich PW, Middleton S, Groot PGd, Wu YP, Harris R, et al. Fibrinogen-coated albumin microcapsules reduce bleeding in severely thrombocytopenic rabbits. Nature Medicine. 1999;5:107-11.

[15] Behrens AM, Sikorski MJ, Li T, Wu ZJ, Griffith BP, Kofinas P. Blood-aggregating hydrogel particles for use as a hemostatic agent. Acta Biomaterialia. 2014;10:701-8.

[16] Chan LWG, Wang X, Wei H, Pozzo LD, White NJ, Pun SH. A Synthetic Fibrin-Crosslinking Polymer for Modulating Clot Properties and Inducing Hemostasis. Science translational medicine. 2015;7:29.

[17] Duggan M, Rago A, Sharma U, Zugates G, Freyman T, Busold R, et al. Self-expanding polyurethane polymer improves survival in a model of noncompressible massive abdominal hemorrhage. The journal of trauma and acute care surgery. 2013;74:1462-7.

[18] Rago AP, Marini J, Duggan MJ, Beagle J, Runyan G, Sharma U, et al. Diagnosis and deployment of a self-expanding foam for abdominal exsanguination: Translational questions for human use. The journal of trauma and acute care surgery. 2015;78:607-13.

[19] Mesar T, Martin D, Lawless R, Podbielski J, Cook M, Underwood S, et al. Human dose confirmation for self-expanding intra-abdominal foam: A translational, adaptive, multicenter trial in recently deceased human subjects. The journal of trauma and acute care surgery. 2015;79:39-47.

[20] Gu BK, Park SJ, Kim MS, Kang CM, Kim J-I, Kim C-H. Fabrication of sonicated chitosan nanofiber mat with enlarged porosity for use as hemostatic materials. Carbohydrate Polymers. 2013;97:65-73.

[21] Okamura Y, Handa M, Suzuki H, Ikeda Y, Takeoka S. New strategy of platelet substitutes for enhancing platelet aggregation at high shear rates: cooperative effects of a mixed system of fibrinogen gamma-chain dodecapeptide- or glycoprotein Ibalpha-conjugated latex beads under flow conditions. J Artif Organs. 2006;9:251-8. 
[22] Palta S, Saroa R, Palta A. Overview of the coagulation system. Indian Journal of Anaesthesia. 2014;58:515-23.

[23] Triplett DA. Coagulation and bleeding disorders: review and update. Clinical chemistry. 2000;46:1260-9.

[24] Narayanan S. Multifunctional roles of thrombin. Annals of clinical and laboratory science. 1999;29:275-80.

[25] MedlinePlus. Bleeding. U.S. National Library of Medicine; 2017.

[26] Shanmuganathan K, Mirvis SE, Sover ER. Value of contrast-enhanced CT in detecting active hemorrhage in patients with blunt abdominal or pelvic trauma. American Journal of Roentgenology. $1993 ; 161: 65-9$.

[27] Fred HL. Drawbacks and Limitations of Computed Tomography: Views from a Medical Educator. Texas Heart Institute Journal. 2004;31:345-8.

[28] Coley BD, Mutabagani KH, Martin LC, Zumberge N, Cooney DR, Caniano DA, et al. Focused Abdominal Sonography for Trauma (FAST) in Children with Blunt Abdominal Trauma. Journal of Trauma and Acute Care Surgery. 2000;48:902-6.

[29] Dawbarn RY, Earlam F, Howel Evans W. The relation of the blood platelets to thrombosis after operationand parturition. The Journal of Pathology and Bacteriology. 1928;31:833-73.

[30] Young G, Sorensen B, Dargaud Y, Negrier C, Brummel-Ziedins K, Key NS. Thrombin generation and whole blood viscoelastic assays in the management of hemophilia: current state of art and future perspectives. Blood. 2013;121:1944-50.

[31] Johansson PI. Coagulation monitoring of the bleeding traumatized patient. Current opinion in anaesthesiology. 2012;25:235-41.

[32] Semon G CM. Thromboelastography in Trauma. Surgical Critical Care Evidence-Based Guidelines Committee. 2014. 
[33] Kashuk JL, Moore EE, Sawyer M, Wohlauer M, Pezold M, Barnett C, et al. Primary fibrinolysis is integral in the pathogenesis of the acute coagulopathy of trauma. Annals of surgery. 2010;252:43442, discussion 43-44.

[34] Paniccia R, Antonucci E, Maggini N, Romano E, Gori AM, Marcucci R, et al. Assessment of platelet function on whole blood by multiple electrode aggregometry in high-risk patients with coronary artery disease receiving antiplatelet therapy. American journal of clinical pathology. 2009;131:834-42.

[35] Brohi K, Cohen MJ, Ganter MT, Matthay MA, Mackersie RC, Pittet J-F. Acute Traumatic Coagulopathy: Initiated by Hypoperfusion: Modulated Through the Protein C Pathway? Annals of surgery. 2007;245:812-8.

[36] Frith D, Davenport R, Brohi K. Acute traumatic coagulopathy. Current opinion in anaesthesiology. 2012;25:229-34.

[37] Chambers L, Chow, S, Shaffer, L. Frequency and characteristics of coagulopathy in trauma patients treated with a low- or high-plasma-content massive transfusion protocol. American journal of clinical pathology. 2011;136:364-70.

[38] Hunt BJ, Segal H. Hyperfibrinolysis. Journal of Clinical Pathology. 1996;49:958.

[39] Lakstein D, Blumenfeld A, Sokolov T, Lin G, Bssorai R, Lynn M, et al. Tourniquets for hemorrhage control on the battlefield: a 4-year accumulated experience. The Journal of trauma. 2003;54:S221-S5.

[40] Rossaint R, Bouillon B, Cerny V, Coats TJ, Duranteau J, Fernández-Mondéjar E, et al. The European guideline on management of major bleeding and coagulopathy following trauma: fourth edition. Critical Care. 2016;20:100.

[41] Brenner M, Stein DM, Hu PF, Aarabi B, Sheth K, Scalea TM. Traditional systolic blood pressure targets underestimate hypotension-induced secondary brain injury. The journal of trauma and acute care surgery. 2012;72:1135-9. 
[42] Van Poucke S, Stevens K, Marcus AE, Lancé M. Hypothermia: effects on platelet function and hemostasis. Thrombosis Journal. 2014;12:31.

[43] Beuran M, Iordache FM. Damage control surgery-new concept or reenacting of a classical idea. Journal of Medicine and Life. 2008;1:247-53.

[44] Manual of Definitive Surgical Trauma Care. Second ed. London: Hodder Arnold; 2007.

[45] Holcomb JB, McMullin NR, Pearse L, Caruso J, Wade CE, Oetjen-Gerdes L, et al. Causes of Death in U.S. Special Operations Forces in the Global War on Terrorism: 2001-2004. Annals of surgery. 2007;245:986-91.

[46] van Oostendorp SE, Tan ECTH, Geeraedts LMG. Prehospital control of life-threatening truncal and junctional haemorrhage is the ultimate challenge in optimizing trauma care; a review of treatment options and their applicability in the civilian trauma setting. Scandinavian Journal of Trauma, Resuscitation and Emergency Medicine. 2016;24:110.

[47] Ruiz C, Andresen M. Treatment of Acute Coagulopathy Associated with Trauma. ISRN Critical Care. $2013 ; 2013: 7$ pages.

[48] Winearls J RM, Miles H, Bulmer A, Campbell D, Görlinger K, Fraser JF. Targeted Coagulation Management in Severe Trauma: The Controversies and the Evidence. Anestesia and Analgesia. 2016;123:910-24.

[49] Binz S, McCollester J, Thomas S, Miller J, Pohlman T, Waxman D, et al. CRASH-2 Study of Tranexamic Acid to Treat Bleeding in Trauma Patients: A Controversy Fueled by Science and Social Media. Journal of Blood Transfusion. 2015;2015:12.

[50] Sorensen B, Bevan D. A critical evaluation of cryoprecipitate for replacement of fibrinogen. British journal of haematology. 2010;149:834-43.

[51] O'Shaughnessy DF, Atterbury C, Bolton Maggs P, Murphy M, Thomas D, Yates S, et al. Guidelines for the use of fresh-frozen plasma, cryoprecipitate and cryosupernatant. British journal of haematology. 2004;126:11-28. 
[52] Besser MW, MacDonald SG. Acquired hypofibrinogenemia: current perspectives. Journal of Blood Medicine. 2016;7:217-25.

[53] Aggarwal A MV, Catlett JP, Alcorn K. Recombinant activated factor VII (rFVIIa) as salvage treatment for intractable hemorrhage. Thrombosis Journal. 2004:9.

[54] Zatta A, McQuilten Z, Kandane-Rathnayake R, Isbister J, Dunkley S, McNeil J, et al. The Australian and New Zealand Haemostasis Registry: ten years of data on off-licence use of recombinant activated factor VII. Blood transfusion $=$ Trasfusione del sangue. 2015;13:86-99.

[55] Ellis-Behnke RG, Liang YX, Tay DK, Kau PW, Schneider GE, Zhang S, et al. Nano hemostat solution: immediate hemostasis at the nanoscale. Nanomedicine : nanotechnology, biology, and medicine. 2006;2:207-15.

[56] Tomiyama Y, Tsubakio T, Piotrowicz R, Kurata Y, Loftus J, Kunicki T. The Arg-Gly-Asp (RGD) recognition site of platelet glycoprotein IIb- IIIa on nonactivated platelets is accessible to high-affinity macromolecules. Blood. 1992;79:2303-12.

[57] Haley B, Frenkel E. Nanoparticles for drug delivery in cancer treatment. Urologic oncology. $2008 ; 26: 57-64$.

[58] Gindy ME, Ji S, Hoye TR, Panagiotopoulos AZ, Prud'homme RK. Preparation of Poly(ethylene glycol) Protected Nanoparticles with Variable Bioconjugate Ligand Density. Biomacromolecules. 2008;9:2705-11.

[59] Gu F, Zhang L, Teply BA, Mann N, Wang A, Radovic-Moreno AF, et al. Precise engineering of targeted nanoparticles by using self-assembled biointegrated block copolymers. Proc Natl Acad Sci U S A. 2008;105:2586-91.

[60] Fakhari A, Baoum A, Siahaan TJ, Le KB, Berkland C. Controlling ligand surface density optimizes nanoparticle binding to ICAM-1. Journal of pharmaceutical sciences. 2011;100:1045-56. [61] Yeh DD, Schecter WP. Primary blast injuries--an updated concise review. World journal of surgery. 2012;36:966-72. 
[62] Prasad S, Cody V, Hanlon D, Edelson RL, Saltzman M, Sasaki CT, et al. Biopolymer nanoparticles as antigen delivery vehicles for immunotherapy of head and neck squamous cell carcinoma (HNSCC). Clinical Otolaryngology. 2008;33:304.

[63] Jain R, Shah NH, Malick AW, Rhodes CT. Controlled drug delivery by biodegradable poly(ester) devices: different preparative approaches. Drug development and industrial pharmacy. $1998 ; 24: 703-27$.

[64] Jain RA. The manufacturing techniques of various drug loaded biodegradable poly(lactide-coglycolide) (PLGA) devices. Biomaterials. 2000;21:2475-90.

[65] Lee IN, Cheng WC, Chung CY, Lee MH, Lin MH, Kuo CH, et al. Dexamethasone reduces brain cell apoptosis and inhibits inflammatory response in rats with intracerebral hemorrhage. Journal of neuroscience research. 2015;93:178-88.

[66] Levy M, Lagarde F, Maraloiu VA, Blanchin MG, Gendron F, Wilhelm C, et al. Degradability of superparamagnetic nanoparticles in a model of intracellular environment: follow-up of magnetic, structural and chemical properties. Nanotechnology. 2010;21:395103.

[67] Shattil SJ, Hoxie JA, Cunningham M, Brass LF. Changes in the platelet membrane glycoprotein IIb.IIIa complex during platelet activation. The Journal of biological chemistry. 1985;260:11107-14. [68] Xiao T, Takagi J, Coller BS, Wang JH, Springer TA. Structural basis for allostery in integrins and binding to fibrinogen-mimetic therapeutics. Nature. 2004;432:59-67.

[69] Takagi J, Petre BM, Walz T, Springer TA. Global conformational rearrangements in integrin extracellular domains in outside-in and inside-out signaling. Cell. 2002;110:599-611.

[70] Kloczewiak M, Timmons S, Hawiger J. Localization of a site interacting with human platelet receptor on carboxy-terminal segment of human fibrinogen gamma chain. Biochemical and biophysical research communications. 1982;107:181-7.

[71] Kramer PA. Letter: Albumin microspheres as vehicles for achieving specificity in drug delivery. Journal of pharmaceutical sciences. 1974;63:1646-7. 
[72] Ikeda Y, Handa M, Kawano K, Kamata T, Murata M, Araki Y, et al. The role of von Willebrand factor and fibrinogen in platelet aggregation under varying shear stress. The Journal of clinical investigation. 1991;87:1234-40.

[73] Takeoka S, Teramura Y, Okamura Y, Handa M, Ikeda Y, Tsuchida E. Fibrinogen-conjugated albumin polymers and their interaction with platelets under flow conditions. Biomacromolecules. 2001;2:1192-7.

[74] John FF. The Role of the Platelet Glycoprotein IIb / IIIa in Thrombosis and Haemostasis. Current Pharmaceutical Design. 2004;10:1567-76.

[75] Hethershaw EL, Cilia La Corte AL, Duval C, Ali M, Grant PJ, Ariens RA, et al. The effect of blood coagulation factor XIII on fibrin clot structure and fibrinolysis. J Thromb Haemost. 2014;12:197-205.

[76] Theusinger OM, Baulig W, Asmis LM, Seifert B, Spahn DR. In vitro factor XIII supplementation increases clot firmness in Rotation Thromboelastometry (ROTEM). Thrombosis and haemostasis. 2010;104:385-91.

[77] Gogolewski S. Selected topics in biomedical polyurethans. A review. Colloid and Polymer Science. 1989;267:757-85.

[78] Zdrahala RJ, Zdrahala IJ. Biomedical applications of polyurethanes: a review of past promises, present realities, and a vibrant future. Journal of biomaterials applications. 1999;14:67-90.

[79] Ravi Kumar MNV. A review of chitin and chitosan applications. Reactive and Functional Polymers. 2000;46:1-27.

[80] Doshi J, Reneker DH. Electrospinning process and applications of electrospun fibers. Journal of Electrostatics. 1995;35:151-60.

[81] M Anderson J, Rodriguez A, T Chang D. Foreign Body Reaction to Biomaterials2008. 
[82] Onuki Y, Bhardwaj U Fau - Papadimitrakopoulos F, Papadimitrakopoulos F Fau - Burgess DJ, Burgess DJ. A review of the biocompatibility of implantable devices: current challenges to overcome foreign body response.

[83] Saini M, Singh Y, Arora P, Arora V, Jain K. Implant biomaterials: A comprehensive review. World Journal of Clinical Cases : WJCC. 2015;3:52-7.

[84] Ulery BD, Nair Ls Fau - Laurencin CT, Laurencin CT. Biomedical Applications of Biodegradable Polymers.

[85] Blok SL, Engels GE, van Oeveren W. In vitro hemocompatibility testing: The importance of fresh blood.

[86] Kelly JF, Ritenour AE, McLaughlin DF, Bagg KA, Apodaca AN, Mallak CT, et al. Injury severity and causes of death from Operation Iraqi Freedom and Operation Enduring Freedom: 2003 2004 versus 2006. The Journal of trauma. 2008;64:S21-S7.

[87] Luchter S, Smith A, Wang J. Fatal Injuries in Light Vehicle Crashes - Time to Death and Cause of Death. Annual Proceedings / Association for the Advancement of Automotive Medicine. 1998;42:277-.

[88] Tien H, Chu PTY, Brenneman F. Causes of death following multiple trauma. Current Orthopaedics. 2004;18:304-10.

[89] Adibhatla RM, Hatcher JF. Tissue Plasminogen Activator (tPA) and Matrix Metalloproteinases in the Pathogenesis of Stroke: Therapeutic Strategies. CNS \& neurological disorders drug targets. 2008;7:243-53

[90] Collen D, Lijnen HR. New approaches to thrombolytic therapy. Arteriosclerosis, Thrombosis, and Vascular Biology. 1984;4:579-85.

[91] Wardlaw JM, Murray V Fau - Berge E, Berge E Fau - del Zoppo GJ, del Zoppo GJ. Thrombolysis for acute ischaemic stroke. 


\section{Figure Legends}

Figure 1: Coagulation cascade. Following injury to the blood vessel, platelets are activated, aggregated and form platelet plug on top of the injury. Activated platelets then trigger the release of clotting factors that activate prothrombin to thrombin. Thrombin converts soluble fibrinogens to nonsoluble fibrins that form fibrin meshwork on top of the platelet plug. Factor XIII is activated by thrombin and stabilizes the fibrin meshwork. The clot typically appears red due to the entrapment of red blood cells in the fibrin meshwork.

Figure 2: (A) Schematic of synthetic platelet made of PLGA-PLL core with PEG arms terminated with RGD. (B) Scanning electron microscope of synthetic platelets. (C) Synthetic platelet interaction with clot via connecting fibrin mesh. (D) Bleeding time of synthetic platelets compared to control injections Reproduced with permission from reference [6].

Figure 3: (A) Schematic of the binding of dexamethasone-loaded nanoparticles (hDNP) to activated platelets. (B) Scanning electron microscope image of hDNP (C) Minimum oxygen saturation in treatment groups after injury. (D) Treatment with hDNP resulted in a significantly lower percent injury Reproduced with permission from reference [9].

Figure 4: Physical models of possible hemostatic mechanisms of the peptide-decorated liposomes and hemostatic effect of constructs. (A) VBP-CBP-decorated liposomal constructs adhere to the vascular injury site and then promote further binding and multimerization of soluble VWF to the available exofacial VBP decorations on the liposome, which in turn can promote further binding of platelets at the site. (B) FMP-decorated liposomal constructs can result in clustering of active platelets onto the liposomes via FMP-to-GPIIb-IIIa interactions and attachment of these clusters at the injury site can be mediated via direct adhesion of the platelets. (C) Functionally integrated constructs show significantly higher hemostatic efficacy possibly because of their capability to undergo enhanced adhesion at the injury site and then promote enhanced platelet recruitment and 
aggregation at that site by both FMP-mediated and VBP-mediated mechanisms. (D) Mice tail bleeding time post-transection show that pre-injection of 'only adhesive' or 'only aggregationpromoting' liposomes resulted in approximately $\sim 50 \%$ decrease in the time for bleeding to stop, and pre-injection with the integrated constructs resulted in $\sim 70 \%$ reduction of bleeding time compared to saline or unmodified liposome injection. Reproduced with permission from reference [11].

Figure 5: Self-propelled calcium carbonate micronanoparticles as hemostatic agents. (A) Schematic showing $\mathrm{CaCO} 3$ particles releasing $\mathrm{CO} 2$ and propelling themselves and their cargo when placed in water. (B) Bleeding times in vivo after the tails of mice were amputated. (C) Schematic showing a mouse liver punctured and treated with propelled thrombin. (D) Volume of blood loss in a separate cohort of mice after their livers were punctured and treated. (E and $\mathbf{F}$ ) Histological sections of livers treated with propelled thrombin (E) or nonpropelled thrombin (F). Fluorescence staining shows actin (red), nuclei (blue), and $\mathrm{CaCO}_{3}$ particles (green). Scale bar, $200 \mu \mathrm{m}$. (G) Mass of $\mathrm{CaCO}_{3}$ delivered to sites of liver puncture. (H) Schematic showing a pig's punctured femoral artery being treated with gauze impregnated with propelled thrombin. (I) Survival of pigs after treatment. $\mathrm{n}=5$. $* \mathrm{P}<0.05,{ }^{* *} \mathrm{P}<0.01$. Error bars indicate SEM. Reproduced with permission from reference [13].

Figure 6: (A) Scanning electron microscope photograph showing interaction of microcapsules and platelet aggregates through connecting fibrin fibers. (B) Micrograph of biopsy from a wound 15 minutes after administration of microcapsules, which shows the presence of microspheres at the site of haemostatic plug. Reproduced with permission from reference [14].

Figure 7: PolySTAT and in vitro characterization of polySTAT-modified fibrin architecture. (A) The polySTAT polymer backbone, a linear statistical copolymer of HEMA and NHSMA synthesized via RAFT polymerization, was grafted with the modified cyclic fibrin-binding peptide AcY(DGl)C(HPr)YGLCYIQGK-Am through NHS ester reaction with lysine $\varepsilon$-amine. DGl, D-g;utamic acid; HPr, hydroxyproline; Ac, acetylated N-terminus; Am, amidated C-terminus. (B) Fully formed 
fibrin clots imaged by scanning electron microscopy to visualize fibrin architecture. hFXIIIa was included for a crosslinking control. Scale bars, $250 \mathrm{~nm}$. Schematics above the SEM images depict the exclusion of non-binding PolySCRAM from fibrin, PolySTAT-induced fibrin crosslinking via binding of fibrin-binding peptides, and enzymatic crosslinking by hFXIIIa. (C) Survival of animals over the 75 -min protocol ( $\mathrm{n}=5$ per treatment). (D) Cumulative blood loss normalized to survival time, including blood lost during catheter hemorrhage, the free bleeding period, and fluid resuscitation. Reproduced with permission from reference [16]. 


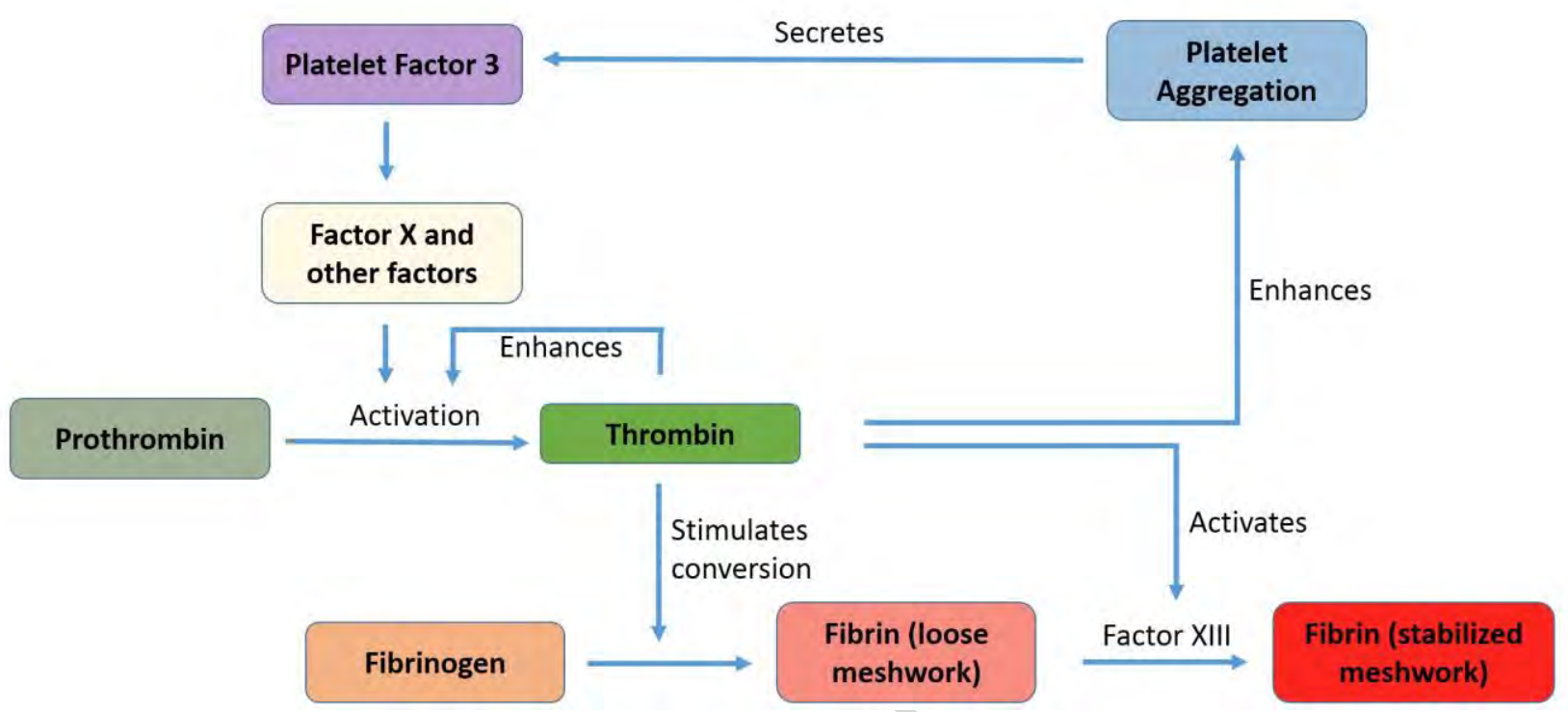

Figure 1 


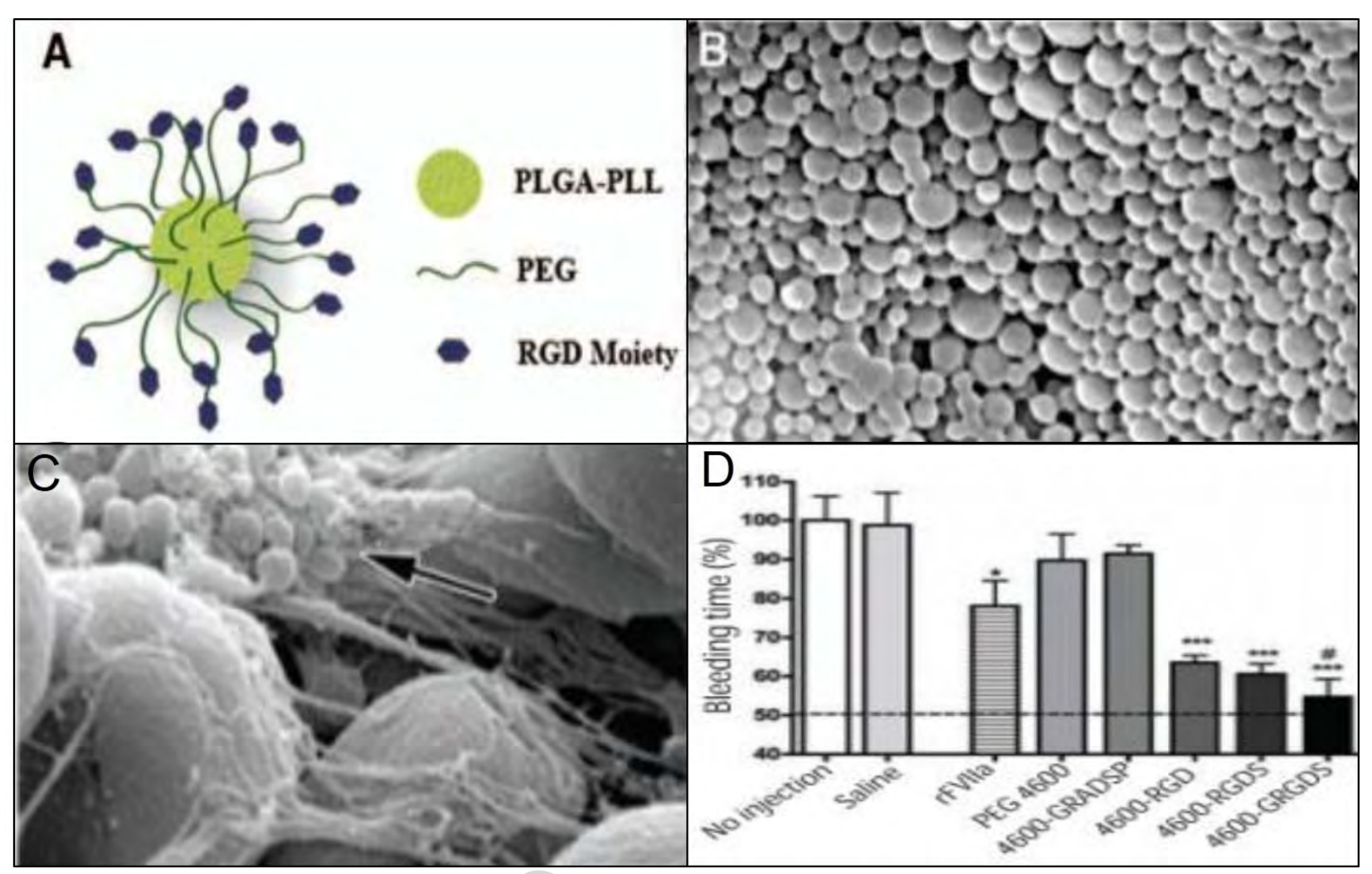

Figure 2 


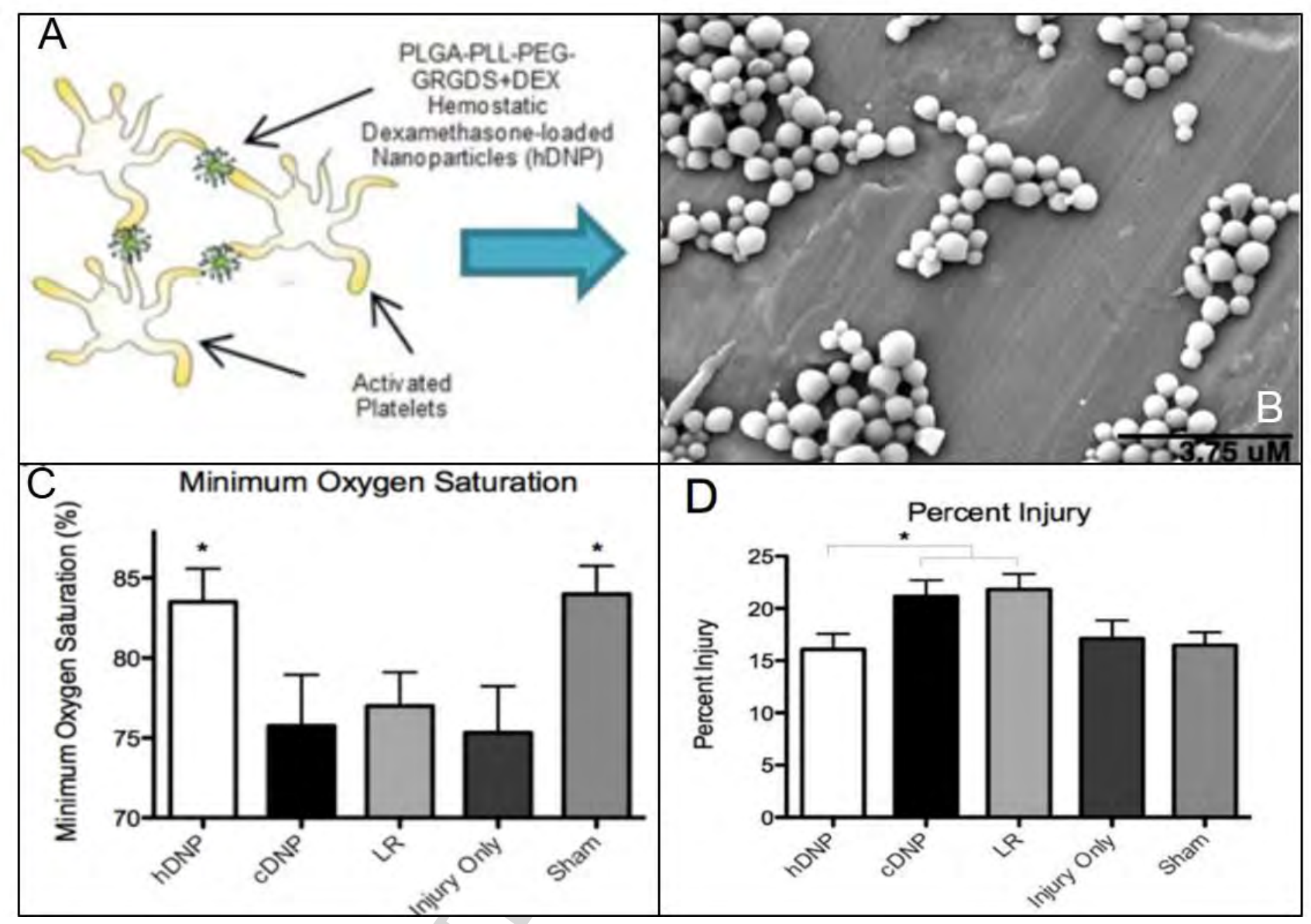

Figure 3 


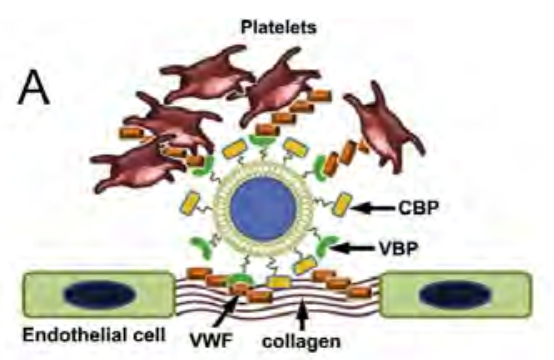

Liposomes bearing only 'adhesive' functionality (VBP plus CBP decorated)



Liposomes bearing only 'aggregation-promoting' functionality (FMP decorated)

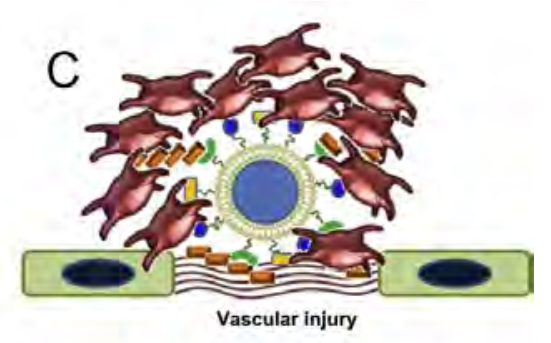

Functionally Integrated Liposomes (VBP plus CBP plus FMP decorated)

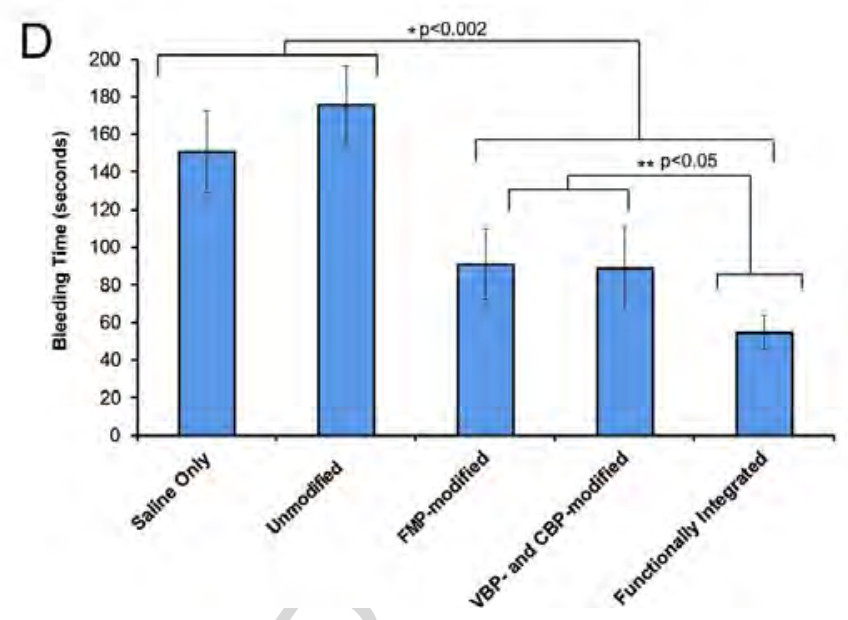

Figure 4 


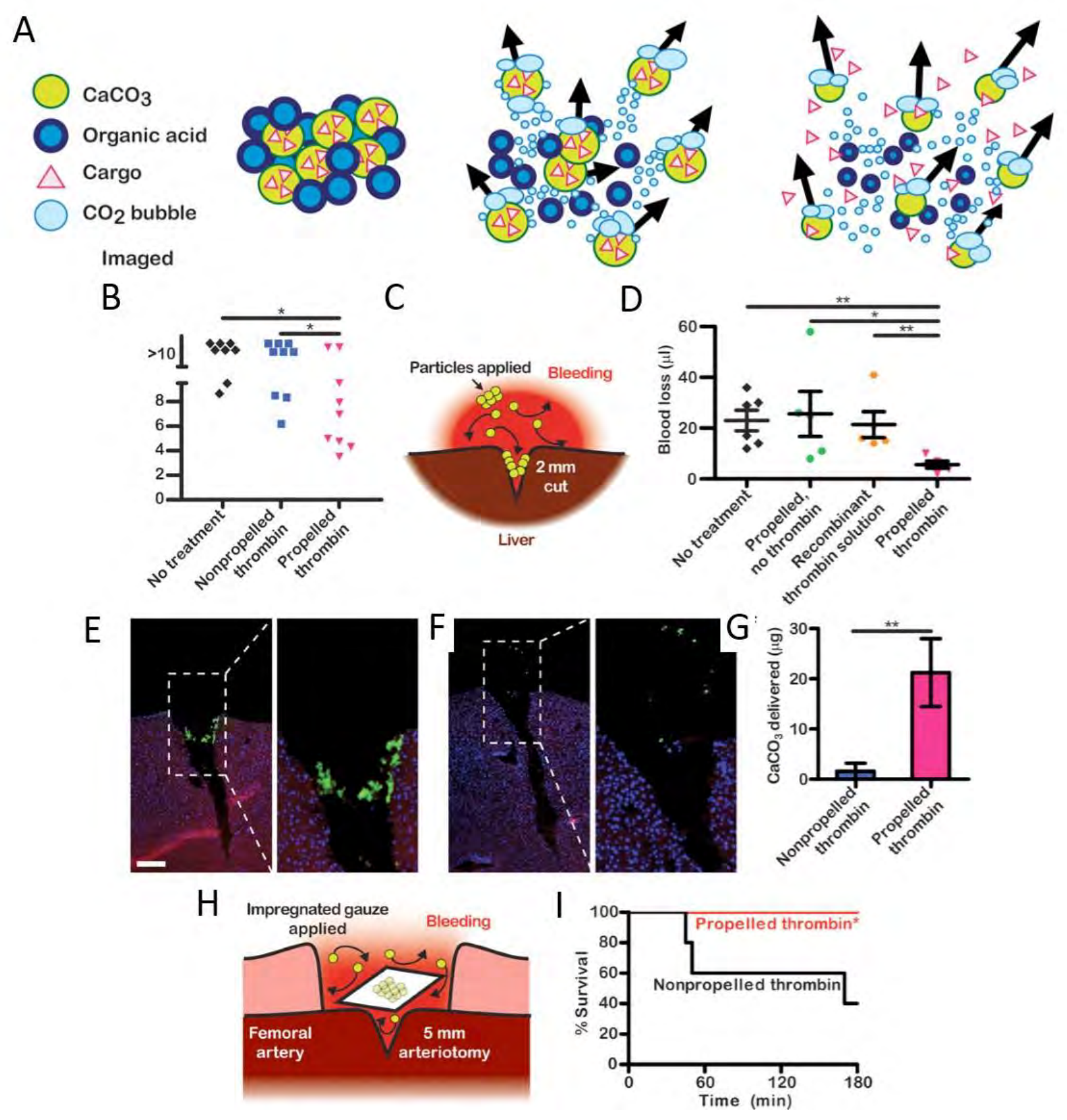

Figure 5 


\section{ACCEPTED MANUSCRIPT}






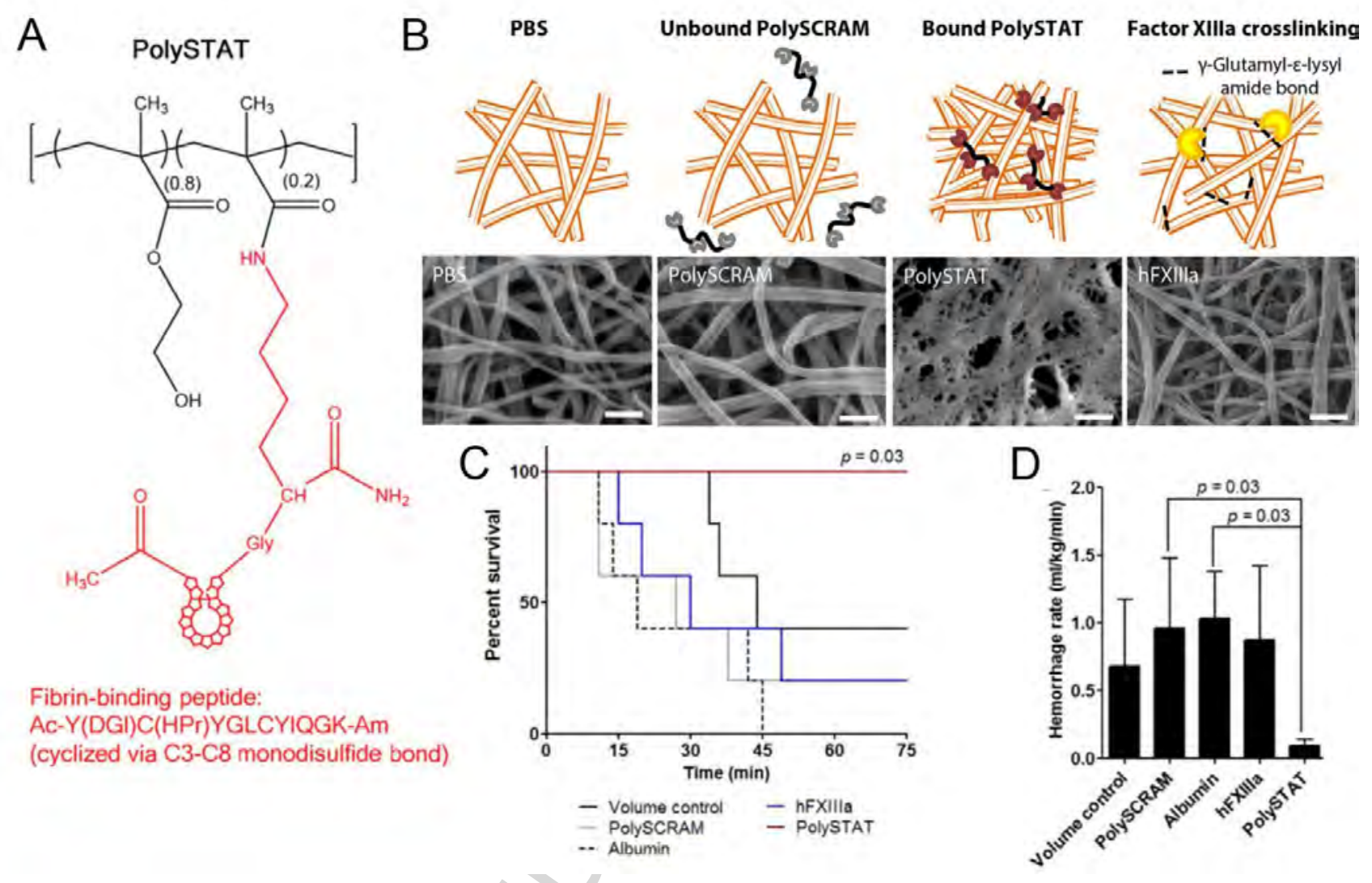

Figure 7 
Table 1: Data values and interpretation for TEG [32]

\begin{tabular}{|l|l|l|l|}
\hline TEG Value & Normal & Description & Measures \\
\hline $\begin{array}{l}\text { TEG-ACT } \\
\text { (rapid) }\end{array}$ & $80-140 \mathrm{sec}$ & $\begin{array}{l}\text { "Activated clotting time" to initial } \\
\text { fibrin formation }\end{array}$ & $\begin{array}{l}\text { clotting factors (extrinsic/intrinsic } \\
\text { pathways) }\end{array}$ \\
\hline $\begin{array}{l}\text { R time } \\
\text { conventional) }\end{array}$ & $5.0-10.0 \mathrm{~min}$ & $\begin{array}{l}\text { "Reaction time" to initial fibrin } \\
\text { formation }\end{array}$ & clotting factors (intrinsic pathway) \\
\hline K time & $1.0-3.0 \mathrm{~min}$ & $\begin{array}{l}\text { "Kinetic time" for fibrin cross linkage } \\
\text { to reach } 29 \text { mm clot strength }\end{array}$ & fibrinogen, platelet number \\
\hline$\alpha$ angle & $\begin{array}{l}53.0-72.0 \\
\text { degrees }\end{array}$ & $\begin{array}{l}\text { Angle from baseline to slope of tracing } \\
\text { that represents clot formation }\end{array}$ & fibrinogen, platelet number \\
\hline MA & $50.0-70.0 \mathrm{~mm}$ & Maximum amplitude of tracing & platelet number and function \\
\hline G value & $\begin{array}{l}5.3-12.4 \\
\text { dynes } / \mathrm{cm}^{2}\end{array}$ & Calculated value of clot strength & entire coagulation cascade \\
\hline LY 30 & $0-3 \%$ & Clot lysis at 30 minutes following MA & fibrinolysis \\
\hline
\end{tabular}


Table 2: Summary of materials studied for the treatment of internal bleeding and trauma haemorrhage

\begin{tabular}{|c|c|c|c|c|c|c|}
\hline Agent & Material & Size & Surface & Shape & Clotting mechanism & Ref. \\
\hline $\begin{array}{l}\text { Synthetic } \\
\text { Platelets }\end{array}$ & $\begin{array}{l}\text { PLGA-PLL- } \\
\text { PEG }\end{array}$ & $170 \mathrm{~nm} \varnothing$ & $\begin{array}{l}\text { Arg-Gly-Asp } \\
\text { (RGD) }\end{array}$ & Nanosphere & $\begin{array}{l}\text { Activated platelets bind to Arg-Gly- } \\
\text { Asp (RGD) sequence on } \\
\text { nanosphere through specific ligand- } \\
\text { receptor interactions }\end{array}$ & [6] \\
\hline $\begin{array}{l}\text { Targeted } \\
\text { Nanoparticles }\end{array}$ & $\begin{array}{l}\text { PLGA-PLL- } \\
\text { PEG }\end{array}$ & $\begin{array}{l}500-600 \mathrm{~nm} \\
\varnothing\end{array}$ & $\begin{array}{l}\text { Arg-Gly-Asp } \\
\text { (RGD) }\end{array}$ & Nanosphere & $\begin{array}{l}\text { Optimizing targeting peptide } \\
\text { (RGD) concentration in order to } \\
\text { improve activated platelet binding }\end{array}$ & [7] \\
\hline $\begin{array}{l}\text { Steroid-Loaded } \\
\text { Hemostatic } \\
\text { Nanoparticles }\end{array}$ & $\begin{array}{l}\text { PLGA-PLL- } \\
\text { PEG }\end{array}$ & $500 \mathrm{~nm} \varnothing$ & $\begin{array}{l}\text { Arg-Gly-Asp } \\
\text { (RGD) }\end{array}$ & Nanosphere & $\begin{array}{l}\text { Activated platelet binding with } \\
\text { RGD in conjugation with the usage } \\
\text { of dexamethasone, a steroid shown } \\
\text { to reduce apoptosis }\end{array}$ & [9] \\
\hline $\begin{array}{l}\text { Silica and Iron } \\
\text { Oxide } \\
\text { Nanoparticles }\end{array}$ & $\begin{array}{l}\text { Silica, Iron } \\
\text { Oxide }\end{array}$ & $50 \mathrm{~nm} \varnothing$ & $\begin{array}{l}\text { Silica aqueous } \\
\text { solution }\end{array}$ & Nanosphere & $\begin{array}{l}\text { Silica nanoparticle aqueous solution } \\
\text { and iron oxide nanoparticles were } \\
\text { directly applied to wound to close } \\
\text { wounds and repair through } \\
\text { nanobridging }\end{array}$ & {$[10]$} \\
\hline $\begin{array}{l}\text { Platelet- } \\
\text { mimetic } \\
\text { liposomal } \\
\text { nanoconstruct }\end{array}$ & Liposomes & $150 \mathrm{~nm} \varnothing$ & $\begin{array}{l}\text { CBP, VBP, } \\
\text { FMP }\end{array}$ & Nanosphere & $\begin{array}{l}\text { The usage of collagen-and-VWF } \\
\text { binding peptides (CBP and VBP) } \\
\text { and Fibrinogen-mimetic peptide } \\
\text { (FMP) to mimic both platelet } \\
\text { adhesion and aggregation }\end{array}$ & [11] \\
\hline $\begin{array}{l}\text { H12-PEG } \\
\text { Vesicles }\end{array}$ & PEG & $220 \mathrm{~nm} \varnothing$ & $\mathrm{H} 12$ & Nanosphere & $\begin{array}{l}\text { The } \\
\text { HHLGGAKQAGDV dodecapeptide } \\
\text { recognizes the active form of } \\
\text { GPIIb/IIIa on the surface of } \\
\text { activated platelets }\end{array}$ & [12] \\
\hline $\begin{array}{l}\text { Platelet- } \\
\text { substituted bead }\end{array}$ & Latex bead & $1 \mu \mathrm{m} \varnothing$ & $\begin{array}{l}\text { H12, } \\
\text { rGPIbalpha }\end{array}$ & Microsphere & $\begin{array}{l}\text { The use of activated platelet } \\
\text { binding peptide (H12) and vWF } \\
\text { binding glycoprotein (rGPIbalpha) } \\
\text { to mimic both platelet aggregation } \\
\text { and adhesion. }\end{array}$ & [21] \\
\hline $\begin{array}{l}\text { Self-propelled } \\
\text { miroparticles }\end{array}$ & $\mathrm{CaCO}_{3}$ & $10 \mu \mathrm{m} \varnothing$ & NA & Microsphere & $\begin{array}{l}\text { Reaction of mixture of } \mathrm{CaCO}_{3} \\
\text { particles and protonated tranexamic } \\
\text { acid in aqueous solutions leads to } \\
\text { rapid production of gas bubbles, } \\
\text { which propels the particles against } \\
\text { blood flow to deliver active } \\
\text { thrombin. }\end{array}$ & [13] \\
\hline $\begin{array}{l}\text { Fibrinogen- } \\
\text { coated albumin } \\
\text { microcapsules }\end{array}$ & Albumin & $\begin{array}{l}3.5-4.5 \mu \mathrm{m} \\
\varnothing\end{array}$ & Fibrinogen & Microsphere & $\begin{array}{l}\text { The coated microcapsules facilitate } \\
\text { platelet adhesion to endothelial cell } \\
\text { matrix }\end{array}$ & [14] \\
\hline $\begin{array}{l}\text { Hydrogel } \\
\text { Microparticles }\end{array}$ & APM & $\begin{array}{l}450-1250 \\
\mu \mathrm{m} \varnothing\end{array}$ & APM & Microsphere & $\begin{array}{l}\text { Hydrogel particles quickly halt } \\
\text { bleeding by rapidly swelling to over } \\
1000 \% \text { in size and forming a robust } \\
\text { haemostatic plug }\end{array}$ & {$[15]$} \\
\hline $\begin{array}{l}\text { Synthetic } \\
\text { Fibrin- } \\
\text { Crosslinking } \\
\text { Polymer }\end{array}$ & $\begin{array}{l}\text { pHEMA-co- } \\
\text { NHSMA }\end{array}$ & $\begin{array}{l}\text { MW: } 4.45 \times \\
10^{4} \mathrm{Da}\end{array}$ & $\begin{array}{l}\text { Cyclicfibrin- } \\
\text { specific } \\
\text { peptide }\end{array}$ & $\begin{array}{l}\text { Linear } \\
\text { statistical } \\
\text { copolymer }\end{array}$ & $\begin{array}{l}\text { Synthetic hemostatic polymer } \\
\text { (PolySTAT) were engineered after } \\
\text { Factor XIIIa to stabilize blood clots } \\
\text { through fibrin crosslinking }\end{array}$ & [16] \\
\hline
\end{tabular}




\begin{tabular}{|l|l|l|l|l|l|}
\hline $\begin{array}{l}\text { Self-expanding } \\
\text { foam }\end{array}$ & Polyurethane & NA & $\begin{array}{l}\text { Polyol phase, } \\
\text { isocyanate } \\
\text { phase }\end{array}$ & NA & $\begin{array}{l}\text { Mixing of the polyol and isocyanate } \\
\text { phase results in a foam that spreads } \\
\text { throughout } \begin{array}{l}\text { abdominal } \\
\text { cavity } \\
\text { creates contact with sites of injury }\end{array}\end{array}$ \\
\hline Nanofiber Mat & Chitosan & NA & Chitosan & Nanofiber & $\begin{array}{l}\text { The structure of the nanofibers } \\
\text { result in super-hydrophobicity and a } \\
\text { density which slows the absorbance } \\
\text { of blood }\end{array}$ \\
\hline
\end{tabular}

